\title{
FACTORS THAT DETERMINE WHEN TO ENGAGE PRE-CONSTRUCTION SERVICES
}

\author{
PAUL BOTHA, DANIEL VAN DER WALT, and ERIC SCHEEPBOUWER \\ Dept of Civil and Natural Resources Engineering, University of Canterbury, Christchurch, \\ New Zealand
}

\begin{abstract}
The use of Pre-Construction Services (PCS) is becoming increasingly common internationally. What remains unclear is defining the optimal stage to engage it. This paper adopted complexity factors to find the optimal moment to engage in PCS. From literature, the factors: schedule-pressure, risk, financing, and technicality were adopted as factors of complexity. Understanding these factors for PCS can help the industry avoid costly PCS pitfalls of engaging in PCS too early or too late. With an online survey, a series of interviews and the analytical hierarchy process, this paper has weighed the above four factors for the key construction stakeholders. This paper concludes that schedule pressure is the most important factor, while technicality is the least important factor for deciding when to engage in PCS. Using these factors and respective weights, it is recommended that a tool be developed that can assist the industry in determining when to engage the contractor for PCS.
\end{abstract}

Keywords: Early contractor involvement, Construction procurement, Project management, Construction collaboration, Stakeholder management, Construction complexity.

\section{INTRODUCTION}

Construction projects are becoming more sophisticated and as a result, early involvement of the contractor in the project life cycle is becoming more common. It provides the client and designers with access to Pre-Construction Services (PCS) from the contractor; this allows for constructability advice, risk identification, and mitigation, plus a review of the construction budget (Rahmani et al. 2013, Song et al. 2009).

In New Zealand, the phases of the construction project are outlined in Figure 1 (NZIA 2020). PCS can occur during any of the phases prior to tender. Defining the ideal time to engage with PCS still remains uncertain; currently, no accepted framework exists to determine when PCS engagement is best suited (van der Walt et al. 2019). This paper seeks to extend the work of van der Walt et al. in clarifying the timing of PCS in the New Zealand construction industry and provide confidence to clients as to when contractor involvement is best suited in the preconstruction phase.

PCS is included in various procurement models. The New Zealand Transport Agency (NZTA) uses a matrix to select the best-suited delivery model for each project. It bases the choice of project-specific characteristics like complexity and scale (NZTA 2019). The traditional delivery system or Design Bid Build (DBB), for instance, utilizes no PCS, while Alliances can rely extensively on PCS. 


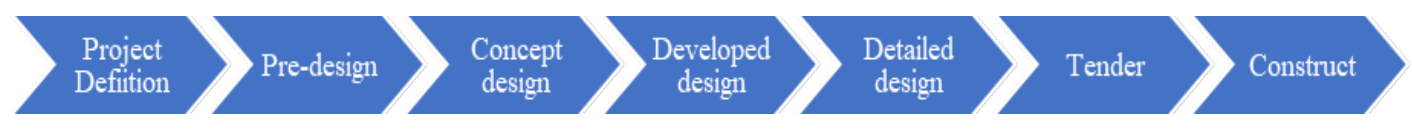

Figure 1. Typical phases before construction in New Zealand adopted from NZIA.

It stands to reason that the optimal time will depend on individual project characteristics. While the scale of a project can be readily quantified (overall project cost), the complexity of a project is not easily defined.

This research attempts to quantify the relationship between the complexity of a project and the optimal timing of PCS.

1) Identify factors to quantify when to engage in PCS.

2) Weigh the factors for each of the key project stakeholders.

3) Compare the weighted factors for different stakeholders.

\section{LITERATURE REVIEW}

All key stakeholders (contractors, consultants, and clients) agree that the early involvement of the contractor is beneficial to project outcomes (van der Walt et al. 2019). The participation of the contractor early in the lifecycle of a project is accepted as having a positive influence on the project (Wondimu et al. 2016). PCS has been found to enhance lean construction principles such as increased schedule performance by reducing steps and cycle times with improved outputs (Pheng et al. 2015). PCS also provides an opportunity to improve the relationships between the parties. This, in turn, benefits the design development and ultimately lead to the successful delivery of the project (Rahman and Alhassan 2012). There are several benefits of having the contractor involved early, such as increased trust, respect, and credibility amongst team members. This leads to improved quality, cost, and schedule performance (Jergeas and Put 2001).

Contractors, consultants, and clients have identified, industry relationships, complexity, and the cost (scale) of projects as influencing factors as to if and when PCS should occur (van der Walt et al. 2019). Reilly (2000) concluded that earlier engagement of a broader range of "stakeholders" is considered for the successful delivery of complex projects.

Botha and Scheepbouwer (2015) investigated the results of 288 projects that were constructed with and without PCS input. The results highlighted significant improvements in cost accuracy and cost performance when PCS was used at appropriate times. They concluded that complex projects benefited most from the engagement of contractors in the pre-construction phase.

Limited research has been conducted on issues of PCS compared to the advantages. However, researchers in Australia have investigated issues associated with partnering arrangements. They investigated six failed partnering projects and collected the contractors' perceptions. Results showed that the client was not willing to fully commit to the agreement. This caused friction between parties, which led to eventual failure. It was recommended that there should be more efficient monitoring of team goals to ensure that the different stakeholders' commitment to the agreement is active ( $\mathrm{Ng}$ et al. 2002).

Eadie and Graham (2014) investigated the advantages and disadvantages of PCS schemes implementation in the UK. Researchers found that often there is a little benefit on smaller or lowrisk projects. Often the PCS schemes resulted in fewer time savings and higher costs (Eadie and Graham 2014, Owen 2009).

Rahmani et al. (2013) argued that for the contractor, PCS could be beneficial as it offers information relating to the clients' holistic viewpoint. Nurturing trust with the client with the goal of retaining the client for future work. Christie et al. (2013) argued that PCS might result in 
less competitive pricing by the contractor. However, they also concluded that this could be minimized by the transparency that results from PCS (Christie et al. 2013).

While many authors have investigated the advantages and disadvantages of PCS, limited research has been done on the timing of PCS. This research looks to extend the research from van der Walt et al. (2019) and further quantify the timing of PCS.

\section{METHODOLOGY}

This research attempts to quantify the relationship between the complexity of a project and the optimal timing of PCS. Project complexity was defined by Gransberg et al. (2013) in the SHRP2-R10 research project into complex projects. They identified the following five dimensions of complex transportation projects: technical, schedule, financing, context, and cost. The NZTA uses ten project-specific characteristics that influence the delivery model selection and hence the inclusion of PCS. For this research, the dimensions defined by Gransberg et al. (2013) and project-specific characteristics by the NZTA have been combined into the complexity factors, as shown in Table 1. Both the NZTA (2019) and Gransberg et al. (2013) identifies that the scale of a project influences the importance of all the factors in Table 1, therefore in developing this methodology project scale was be considered to be an amplifier and not considered for further analysis here. However, it is recommended that further research be completed to understand how the scale of a project impacts the factors in Table 1 .

Table 1. Factors determining complexity adopted from Gransberg et al. (2013) and NZTA (2019).

\begin{tabular}{|l|}
\hline \multicolumn{1}{|c|}{ Complexity factors } \\
\hline - \\
$\begin{array}{l}\text { Technicality: inter-disciplinary challenges and issues in an } \\
\text { engineering/construction context. }\end{array}$ \\
\hline $\begin{array}{l}\text { Schedule Pressures: urgency caused by having too many } \\
\text { demands on time or resources. }\end{array}$ \\
\hline $\begin{array}{l}\text { Financing: source, schedule and distribution of funds, } \\
\text { which may lead to limited opportunities for a project. (Not } \\
\text { cost). }\end{array}$ \\
\hline - Risk: Uncontrollable circumstances from internal and \\
external sources that could impact project progress.
\end{tabular}

The Analytical Hierarchy Process (AHP) (Saaty 2008) was used to determine which of the above four factors are most critical. AHP is a multi-criteria decision-making method that permits the relative assessment and prioritization of alternatives. The AHP process is based on the use of pairwise comparisons, which leads to the elaboration of a ratio scale. AHP uses a model of the decision problem as a hierarchy, consisting of an overall goal, a group of alternatives, and a group of criteria that link the alternatives to the goal (Vidal et al. 2011). With the refined definition of project complexity, an AHP hierarchal structure can be built. The overall objective is to find the weighting of each complexity factor, meaning the AHP score, which is obtained ranks and aggregates the importance of each complexity factor.

Table 2. Background of the survey participants.

\begin{tabular}{|c|c|c|}
\hline Contractors & Consultants & Clients \\
\hline $35 \%$ & $39 \%$ & $26 \%$ \\
\hline
\end{tabular}


To collect data for the AHP analysis and understand expert reasoning, surveys and exploratory interviews were used. According to Michelsen and de Boer (2009), as well as Schvaneveldt and Adams (1991), these two methods are an effective way of gathering information from experts. Exploratory interviews support the survey data through the understanding of nuances, systematic, and holistic factors. A total of 35 engineering professionals with a minimum of 10 years of relevant experience in the New Zealand construction industry were selected to participate. Interviews were face to face and lasted approximately 60 minutes. The online survey was conducted using a combination of multi-choice, long answer, and short answer questions. The online survey focused on collecting data for the AHP analysis, whereas interviews focused on holistic understanding and expert reasoning. Table 2 shows the proportion of the 35 participants working in each field.

\section{RESULTS}

AHP was used to determine the relative importance of each complexity factor. The validity of the results obtained was verified through the AHP consistency ratio (CR) check. This value should be less than 0.15 for a group to ensure that the pairwise comparisons are consistent (Ho et al. 2005). The weighting of the factors was further calculated based upon specialization within the construction industry. This allowed for the perspectives of contractors, consultants, and clients to be identified separately. The results are summarized in Table 3.

Table 3. Complexity factors weighting according to the stakeholders.

\begin{tabular}{|c|c|c|c|}
\hline Factor & Contractor & Consultant & Client \\
\hline Risk & 0.39 & 0.23 & 0.29 \\
\hline Schedule Pressures & 0.30 & 0.38 & 0.38 \\
\hline Financing & 0.18 & 0.23 & 0.10 \\
\hline Technicality & 0.13 & 0.14 & 0.23 \\
\hline Consistency Ratio (CR) & 0.057 & 0.116 & 0.057 \\
\hline
\end{tabular}

From the results in Table 3, the risk is the most important factor for contractors. Unforeseen events that occur on a project can have significant financial implications as contractors are usually liable for any losses that may occur during construction. To mitigate this, the contactor prefers to be engaged earlier in the pre-construction phase. Contractors ranked schedule pressure a close second. Early engagement of PCS can alleviate the demand placed on resources due to time constraints imposed. Risk and schedule pressure are ranked significantly higher than financing and technicality because the former are outside the control of the contractor. Contractors do not view 'financing' as important; most construction projects in New Zealand are publicly funded. Therefore, do not provide any challenges to the contractor. Technicality is considered the least important factor when deciding to get involved in PCS for both the contractor and consultant as this is controlled under their domain.

Schedule pressure was the highest weighted factor for the consultants. Consultants prefer the contractors involved earlier when there is significant time pressure. Consultants view risk and financing as second equal to deciding to engage the contractor. The risk register on projects is being developed early on during the design. Contractor input for construction risks can mitigate the consultants' risk concerns. 
Schedule pressure is the most important factor for clients. Having the contractor involved early can speed up the design phase. In addition, the construction industry in New Zealand is resource constraint and clients have concerns about the availability within the market to perform timely work.

The client recognizes risk as to the second most important factor and technicality was ranked third most important. Clients often do not have the in-house technical skills to deliver a project and rely on the skills from consultants' and contractors' staff. Most clients in New Zealand have an annual budget for spending on infrastructure, which means they don't necessarily have to apply for funding; therefore, this has a lesser impact on the decision as to when to engage in PCS.

\section{CONCLUSIONS}

From the literature reviewed, this research identified complexity factors to quantify when to engage in PCS. The factors identified are risk, schedule pressure, financing, technicality, and scale (cost). These factors are used to signal the need for collaboration between client, contractor, and consultant. The various stakeholders have different views on the importance of each factor on the optimal timing of PCS. The contractors put a much higher weight on risk due to the financial implications. The consultants suggest that early engagement of PCS can alleviate schedule pleasure, the while for the contractor, early engagement of PCS helps manage construction risk. Technicality is ranked low by contractors and consultants because of the level of skills available within their organizations. Clients view technicality as more important because they do not have the in-house technical skills. Holistically, project success depends on value for money and the timely delivery of the project. Although stakeholders have differing views on what drives the timing of PCS, all agree that PCS is beneficial. Therefore, there is a need to develop a framework to optimize the timing of PCS to get the best outcome for all involved. The following recommendations are made:

- It is recommended that the influence of the project scale on the timing of PCS be investigated.

- A decision-making framework and tool should be developed to define the optimal time for PCS.

\section{References}

Botha, P. S., and Scheepbouwer, E., Relationship between Early Contractor Involvement and Financial Performance in The Rebuild of Christchurch's Infrastructure, Transportation Research Board 94th Annual Meeting, 2015.

Christie, G., Weatherhall, M., Curran, L., Fox, C., and Vitas, S., ECI: What is it. Why Use it and Where is it Going?, Simpson Grierson, Retrieved October, 27, 2013.

Eadie, R., and Graham, M., Analysing the Advantages of Early Contractor Involvement, International Journal of Procurement Management, 7(6), 661-676, 2014.

Gransberg, D. D., Shane, J. S., Strong, K., and del Puerto, C. L., Project Complexity Mapping In Five Dimensions For Complex Transportation Projects, Journal of Management in Engineering, 29(4), 316326, 2013.

Ho, D., Newell, G., and Walker, A., The Importance of Property-Specific Attributes in Assessing CBD Office Building Quality, Journal of Property Investment and Finance, 23(5), 424-444, 2005.

Jergeas, G., and Put, J. V. D., Benefits of Constructability on Construction Projects, Journal of Construction Engineering and Management, 127(4), 281-290, 2001.

Michelsen, O., and de Boer, L., Green Procurement In Norway; A Survey of Practices at the Municipal and County Level, Journal of Environmental Management, 91(1), 160-167, 2009.

Ng, S. T., Rose, T. M., Mak, M., and Chen, S. E., Problematic Issues Associated with Project PartneringThe Contractor Perspective, International Journal of Project Management, 20(6), 437-449, 2002. 
NZIA, The design process and project phases. Retrieved from https://www.nzia.co.nz/connect/workingwith-an-architect/the-design-process on September 2020.

NZTA., Procurement Manual [Online], 2019. Retrieved from www.nzta.govt.nz on January 28, 2020.

Owen, E., Highways Agency to Review ECI, 2009. New Civil Engineer. Retrieved from www.nce.co.uk/highways-agency-to-review-eci/5200210 on August 2011.

Pheng, L. S., Gao, S., and Lin, J. L., Converging Early Contractor Involvement (ECI) and Lean Construction Practices for Productivity Enhancement: Some Preliminary Findings from Singapore, International Journal of Productivity and Performance Management, 64(6), 831-852, 2015.

Rahman, M., and Alhassan, A., A Contractor's Perception on Early Contractor Involvement, Built Environment Project and Asset Management, 2(2), 217-233, 2012.

Rahmani, F., Khalfan, M., Maqsood, T., Noor, M., and Alshanbri, N., How Can Trust Facilitate The Implementation of Early Contractor Involvement (ECI)?,CIB Symposium 2013, CIB World Building Congress, 2013.

Reilly, J., The Management Process for Complex Underground and Tunneling Projects, Tunnelling and Underground Space Technology, 15(1), 31-44, 2000.

Saaty, T. L., Decision Making with the Analytic Hierarchy Process, International Journal of Services Sciences, 1(1), 83-98, 2008.

Schvaneveldt, J. D., and Adams, G, Understanding Research Methods, Longman, New York, 1991.

Song, L., Mohamed, Y., and AbouRizk, S. M., Early Contractor Involvement in Design and Its Impact on Construction Schedule Performance, Journal of Management in Engineering, 25(1), 12-20, 2009.

van der Walt, J. D., Botha, P. S., and Scheepbouwer, E., When to Engage the Contractor for PreConstruction Services in New Zealand, Transportation Research Record, 2673(2), 562-570, 2019.

Vidal, L.-A., Marle, F., and Bocquet, J. C., Measuring Project Complexity Using The Analytic Hierarchy Process, International Journal of Project Management, 29(6), 718-727, 2011.

Wondimu, P. A., Hailemichael, E., Hosseini, A., Lohne, J., Torp, O., and Lædre, O., Success Factors for Early Contractor Involvement (ECI) in Public Infrastructure Projects, Energy Procedia, 96, 845-854, 2016. 